\title{
Variation Associated with Silk Channel Inoculation for Common Smut of Sweet Corn
}

\author{
Lindsey J. du Toit and Jerald K. Pataky, Department of Crop Sciences, University of Illinois, Urbana 61801
}

\begin{abstract}
du Toit, L. J., and Pataky, J. K. 1999. Variation associated with silk channel inoculation for common smut of sweet corn. Plant Dis. 83:727-732.

Efforts at breeding for resistance to common smut of maize (Zea mays), caused by Ustilago maydis, are hampered by the lack of a reliable and efficient method of inoculation. Silk channel injection is one of the most efficient methods of inoculating for ear galls but is less consistent than acceptable for accurate assessment of the response of genotypes. The objective of this study was to examine how the silk channel inoculation method can be modified to reduce variation while maintaining efficiency for large-scale field inoculations. Variation associated with inoculum concentration and variation among people inoculating were examined. Incidence and severity of symptomatic ears increased with inoculum concentration. Concentrations between $10^{5}$ and $10^{6}$ sporidia/ml are recommended. Variation among people was greater than variation among inoculum concentrations. Incidence and severity ratings were lower for people inexperienced at inoculating with $U$. maydis than for experienced people. Variation among people inoculating can be controlled by appropriate experimental design.
\end{abstract}

Common smut of maize (Zea mays), caused by Ustilago maydis (DC.) Corda (= U. zeae (Beckm.) Unger), occurs in areas of maize production throughout the world. Host resistance is the most efficient method of controlling common smut. Resistance to common smut has been incorporated into field maize by eliminating lines with smut from breeding programs. Sweet corn is less resistant than field maize, probably because of less diligence by sweet corn breeders at removing symptomatic lines, and because of a lack of resistance in the germ plasm from which modern sweet corn inbreds are derived. Galls on ears are particularly destructive in sweet corn because of reduction in quality and additional costs of harvesting and processing infected ears (1).

Response to natural infection by $U$. maydis often is the basis by which maize inbreds or hybrids are classified as resistant or susceptible to smut and is the main criterion for eliminating smut-susceptible lines in breeding programs. Trials based on natural infection are unreliable because of the erratic occurrence of environmental conditions conducive to smut infection (3), and because of associations between host

Corresponding author: J. K. Pataky

E-mail: j-pataky@uiuc.edu

Present address of L. J. du Toit: Washington State University, 7612 Pioneer Way E, Puyallup 983714998.

Accepted for publication 19 March 1999.

Publication no. D-1999-0503-05R

(C) 1999 The American Phytopathological Society growth stage at the time of infection and plant tissues on which galls develop $(5,13)$. An efficient and reliable method of inoculating with $U$. maydis would improve breeding for resistance to common smut in sweet corn.

Walter (17) and Christensen (1) reviewed studies on methods of inoculating for common smut of maize, most of which induced stalk, leaf, and tassel galls. Losses due to common smut in sweet corn are associated mainly with ear galls, and studies in the past 10 years have focused on ear infection $(6-8,11,18)$. Ear galls are induced by injecting a sporidial suspension into the silk channel or through husk leaves soon after silks emerge. A silk channel inoculation technique developed for use in field experiments and breeding programs resulted in a higher incidence of ears with galls than natural infection, but reactions of hybrids were inconsistent among trials (7).

The objective of this study was to identify sources of variation associated with the silk channel method of inoculating for common smut in order to modify the method and minimize variation in largescale field trials. To meet this objective, we determined (i) a method of producing large volumes of inoculum that is rapid and efficient, (ii) the effects of a range of concentrations of inoculum on development of ear galls, and (iii) the relative importance of variation among people applying inoculum using the silk channel method. Preliminary results have been reported (2).

\section{MATERIALS AND METHODS}

Production of inoculum. The method described by Snetselaar and Mims (11) was used to produce inoculum. Compatible isolates of $U$. maydis, isolate 521 of mating type $a 1 b 1$ and isolate 518 of mating type $a 2 b 2$ (obtained from K. M. Snetselaar, St. Joseph's University, Philadelphia), were maintained on potato dextrose agar (PDA). Liquid cultures were prepared by seeding $50 \mathrm{ml}$ of sterile potato dextrose broth (PDB) with sporidia scraped from PDA plates using an inoculating loop. The PDB cultures of $U$. maydis were incubated on a shaker at room temperature for 18 to $24 \mathrm{~h}$. Flasks of sterile PDB were seeded with aliquots of liquid culture at a ratio of approximately $0.5 \mathrm{ml}$ sporidial suspension to $100 \mathrm{ml}$ sterile PDB. The volume of PDB seeded varied depending on the amount of inoculum required for field inoculations. Cultures were incubated on a shaker for 12 to $18 \mathrm{~h}$, then centrifuged at 7,500 rpm for 6 min. The supernatant was discarded and the sporidial pellet was resuspended in a volume of distilled water equal to the volume of discarded supernatant. The suspension was adjusted to the appropriate concentration by dilution with distilled tap water.

The regression relationship between concentration of sporidia, based on hemocytometer counts, and absorbance of the sporidial suspension, based on spectrophotometer readings, was calculated for each isolate of $U$. maydis in order to determine the concentration of sporidia rapidly so that large volumes of inoculum could be prepared efficiently. The two isolates were grown separately in PDB as described above. A 5-ml aliquot was sampled every 2 to $4 \mathrm{~h}$ from 12 to $24 \mathrm{~h}$ after seeding. At each sampling interval, the number of sporidia per milliliter was counted using a hemocytometer and absorbance of the sporidial suspension was measured using a spectrophotometer $(\lambda=$ $590 \mathrm{~nm})$. These calibrations were repeated twice. Regression equations were calculated using Proc GLM of SAS (version 6.12; SAS Institute, Cary, NC).

Nutrient deprivation. In 1995, inoculum was prepared for all trials using the protocol described above. Centrifugation and resuspension of sporidia to enhance the mating efficiency of isolates were the most time-consuming steps in preparing inoculum. The effects of these steps were evaluated in 1996. The sweet corn hybrid Phenomenal was planted on 20 May 1996 at the University of Illinois South Farm. The experiment was arranged as a randomized complete block (RCB) design with four replications. Treatments were the two 
methods of preparing inoculum: inoculum prepared by centrifuging sporidial suspensions and resuspending them in water prior to mixing compatible isolates, or inoculum prepared without centrifugation prior to mixing compatible isolates. An experimental unit was an eight-row plot. Rows were $3 \mathrm{~m}$ long and spaced $0.76 \mathrm{~m}$ apart with about 15 plants/row. The primary ears of 50 plants/ experimental unit were inoculated on 21 or 23 July 1996, when silks had emerged 1 to 2 $\mathrm{cm}$. Each ear was inoculated by injecting 3 $\mathrm{ml}$ of a suspension of compatible sporidia (approximately $10^{6}$ sporidia $/ \mathrm{ml}$ ) down the silk channel using a hog vaccinator (50-cc pistol grip vaco syringe, Model ID65, Ideal Instruments, Chicago) equipped with a stainless steel needle ( $35 \mathrm{~mm}$ long and $3 \mathrm{~mm}$ in diameter) that was blocked at the tip and had two small holes in the side for release of inoculum.

Ears with galls were counted and severity of ear galls was rated approximately 3 weeks after inoculation. Incidence was calculated as the percentage of ears with galls relative to the number of ears inoculated. Severity of ear galls was rated on an ear basis as percentage of the ear with galls, in increments of $10 \%$. Severity of smutted ears per plot was calculated as the mean severity of smut per infected ear. The analysis of variance (ANOVA) and Levene's test for homogeneity of treatment variances were calculated using Proc GLM of SAS.

Concentration of inoculum. The effect of inoculum concentration on development of ear galls of common smut was examined in field trials at the University of Illinois South Farm from 1995 to 1997. Eight sweet corn hybrids (Chieftan, Daystar, Frontier, GSS 7887, Primetime, Punchline, Sch 5005, and Ultimate) were planted on 5 June 1995. Six hybrids (Dazzle, GH 2690, Primetime, Punchline, Temptation, and Ultimate) were planted on 23 May 1996

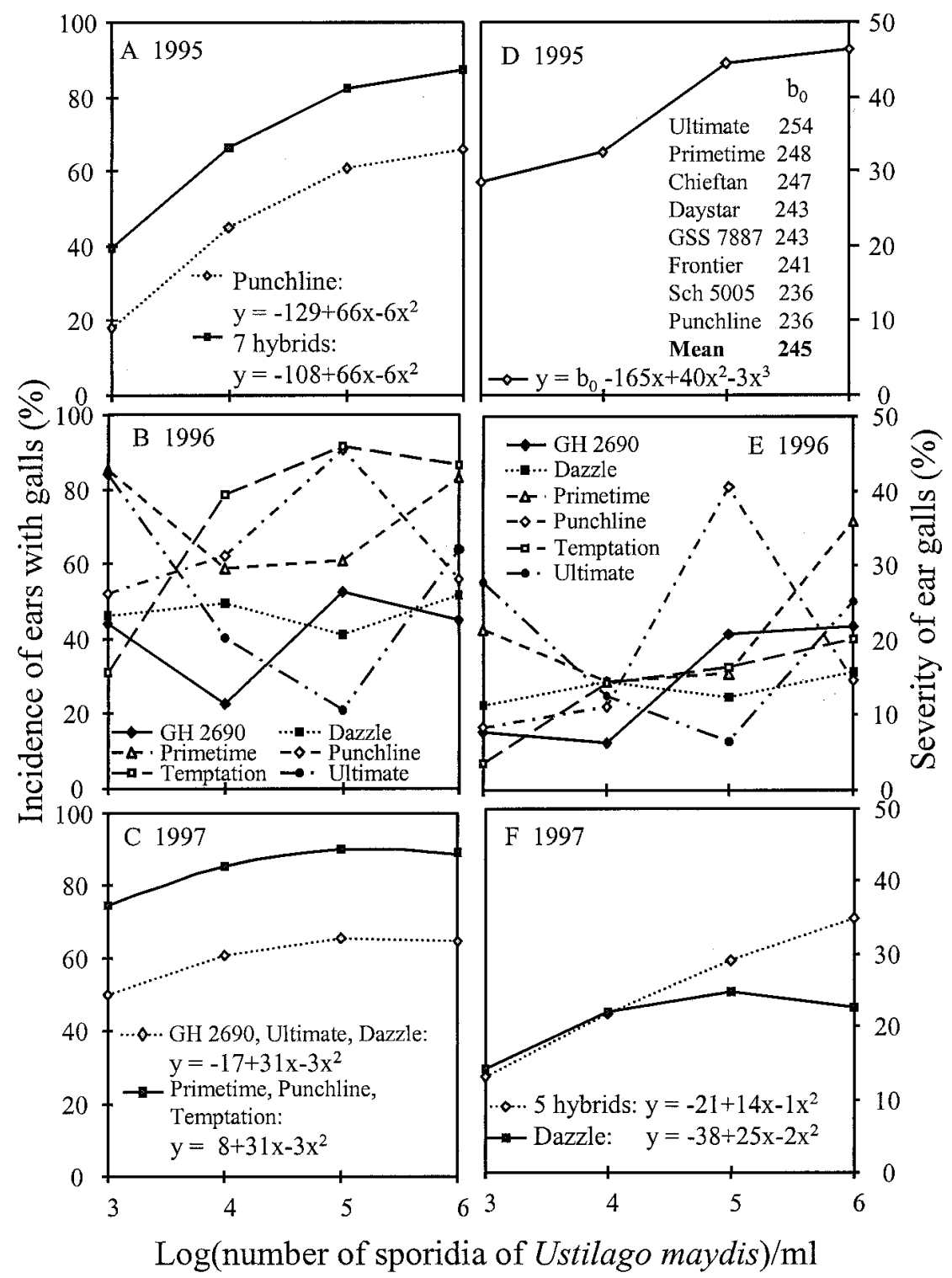

Fig. 1. Relationship between (A, B, C) incidence of ears with galls and (D, E, F) severity of ear galls of common smut on sweet corn inoculated with different concentrations of Ustilago maydis. and 12 May 1997. The experimental design was a split-plot RCB design with four replications each year. Hybrids were assigned to main plots. Four concentrations of inoculum $\left(10^{3}, 10^{4}, 10^{5}\right.$, and $10^{6}$ sporidia/ml) were the treatments applied to split plots. An experimental unit was an eight-row plot. Rows were $3 \mathrm{~m}$ long and spaced $0.76 \mathrm{~m}$ apart with approximately 15 plants/row.

Inoculum was prepared using the protocol described above. Centrifugation and resuspension steps were not included in the protocol in 1997. Inoculum was diluted to the appropriate concentrations with distilled tap water and stored on ice until the two isolates were mixed immediately prior to inoculation. The primary ear of each plant was inoculated by injecting $3 \mathrm{ml}$ of a suspension of compatible isolates at the appropriate concentration down the silk channel when silks had emerged 1 to $2 \mathrm{~cm}$. Ears were inoculated on 4 August 1995. Plants not silking by 4 August were removed. In 1996 and 1997, hybrids were inoculated individually based on maturity. To minimize variation in maturity among inoculated plants, 50 plants with silks emerged 1 to $2 \mathrm{~cm}$ were tagged in each experimental unit one day prior to inoculation of each hybrid. Tagged plants were inoculated. An additional 50 plants of similar maturity were marked with tags in each replication as noninoculated control plants. Plants were inoculated on 19, 25, 27, 29, and 31 July 1996 for the hybrids Temptation, Punchline, Dazzle, Ultimate and Primetime, and GH 2690, respectively; and on 15, 21, 23, 25, and 26 July 1997 for the hybrids Temptation, Punchline, Primetime and Dazzle, Ultimate, and GH 2690, respectively. People inoculating were blocked by concentration of inoculum in 1995 and 1996, thus confounding variation among people with variation due to concentration of inoculum. As a result of apparent systematic variation in incidence of ear galls among people inoculating in the 1996 trial, people inoculating in 1997 were blocked by replication.

The primary ear of each tagged plant was harvested and husked 15 to 20 days after inoculation. Incidence of ears with galls and severity of ear galls were rated as described above. Weight of symptomatic ears per plot was measured in 1995 to calculate weight per severity as: (weight per smutted ear)/(severity per smutted ear). Infected ears were not weighed in 1996 or 1997.

The ANOVA for incidence, severity, and weight of infected ears/severity, and regression equations describing the relationship between incidence or severity with concentration of inoculum, were calculated using Proc GLM of SAS. The 1995 trial was analyzed separately from the 1996 and 1997 trials because of the different set of hybrids evaluated in 1995. A separate ANOVA also was calculated for each of 
the 1996 and 1997 trials because of significant interactions between years, hybrids, and concentration of inoculum in the ANOVA combined over years. Hybrid means were separated using Fisher's protected least significant difference (LSD) in years with a significant main effect for hybrids but no significant interaction between hybrids and concentration of inoculum. Regression equations were pooled for hybrids that were not significantly different.

Variation among people inoculating. Variation among people inoculating relative to variation among inoculum concentrations was examined from the 1996 and 1997 concentration studies, and from a separate experiment in 1997. In the 1997 concentration study, deviations in incidence of ears with galls and severity of ear galls from the best linear unbiased estimates (BLUEs) of incidence and severity were calculated for each person at each concentration for all hybrids. The BLUEs of incidence and severity were the predicted incidence and severity ratings based on the regression models derived from the 1997 concentration study (Fig. 1C and F). Deviations in incidence and severity for each person were averaged over all hybrids and concentrations to produce a mean deviation per person. Mean deviations were compared using $t$ tests (12) to identify people whose inoculations resulted in high incidence and severity ratings (mean deviations $>0$ ) and those whose inoculations resulted in low incidence and severity ratings (mean deviations <0). Deviations in incidence and severity were plotted against concentration of inoculum for each person to examine variation within and among people inoculating.

In the 1996 concentration study, people were blocked by concentration. Of seven people carrying out inoculations over the duration of the study, only one person inoculated all four concentrations; therefore, mean deviations from the BLUEs of incidence and severity could not be calculated for all people.

The magnitude of variation among people carrying out inoculations also was ex- amined in a separate experiment in 1997. The treatment design was a factorial combination of four concentrations of inoculum $\left(10^{3}, 10^{4}, 10^{5}\right.$, and $10^{6}$ sporidia/ml $)$ and eight people inoculating. The experiment was planted as a split-plot RCB design with four replications. Main-plot treatments were concentrations of inoculum, and split-plot treatments were people inoculating. An experimental unit was a four-row plot. Rows were $3 \mathrm{~m}$ long with approximately 15 plants/row and a rowspacing of $0.76 \mathrm{~m}$.

The sweet corn hybrid Dazzle was planted on 12 May 1997 on the University of Illinois South Farm. Plants were inoculated on 26 July 1997. The primary ear of each plant was inoculated when silks had emerged 1 to $2 \mathrm{~cm}$, as described for the inoculum concentration study. Ears with silks not yet emerged or with silks too mature (brown tips) on 26 July were removed. Inoculum for each concentration was stored on ice until compatible isolates were mixed immediately prior to inoculating. Ears were harvested, husked, and rated for development of ear galls on 14 August 1997. Incidence of ears with galls and severity of ear galls per plot were calculated as described above. The ANOVA for incidence and severity were calculated using Proc GLM of SAS. Regression equations describing the relationships between incidence or severity with concentration of inoculum were calculated for each person inoculating. Regression equations were pooled when intercepts and slope coefficients were not significantly different.

\section{RESULTS}

Production of inoculum. Concentration of sporidia and absorbance of the sporidial suspension for each isolate of $U$. maydis were related as described by the following regression equations: for isolate 518 (mating type $a 2 b 2) \hat{\mathrm{Y}}=2.6+9.3 X\left(r^{2}=\right.$ 0.53 , coefficient of variation $[\mathrm{CV}]=20 \%$ ); and for isolate 521 (mating type $a 1 b 1$ ): $\hat{\mathrm{Y}}$ $=2.1+4.8 X\left(r^{2}=0.60, \mathrm{CV}=15 \%\right)$; where $\hat{\mathrm{Y}}=($ number of sporidia $/ \mathrm{ml}) \times 10^{6}$ based on hemocytometer counts, and $X=$ absor- bance of the sporidial suspension measured with a spectrophotometer $(\lambda=590 \mathrm{~nm})$. These regression models were used to determine concentration of sporidia more rapidly based on spectrophotometer absorbance readings rather than on hemocytometer counts of sporidia.

Nutrient deprivation. Incidence of ears with galls ranged from 80 to $96 \%$ with a mean of $90 \%$. Severity of ear galls ranged from 34 to $40 \%$ with a mean of $38 \%$. Incidence and severity did not differ significantly between plots inoculated with centrifuged inoculum and plots inoculated with non-centrifuged inoculum. Variances were homogeneous for the two methods of preparing inoculum, both for incidence of ears with galls $(P=0.116)$ and for severity of ear galls $(P=0.796)$.

Concentration of inoculum. Incidence of ears with galls ranged from 6 to $100 \%$ with a mean of $63 \%$ in 1995 , from 9 to $98 \%$ with a mean of $58 \%$ in 1996 , and from 23 to $100 \%$ with a mean of $73 \%$ in 1997. Incidence in noninoculated experimental units ranged from 0 to $56 \%$ in 1995 , from 0 to $8 \%$ in 1996 , and from 0 to $16 \%$ in 1997. Incidence of ears with galls differed among hybrids each year and among concentrations of inoculum in 1995 and 1997 (Table 1). The relationship between incidence of ears with galls and concentration of inoculum did not differ among hybrids in 1995 or in 1997, but there was a significant interaction between hybrids and concentration of inoculum in 1996.

Incidence of ears with galls increased with concentration of inoculum for all hybrids in 1995 (Fig. 1A) and 1997 (Fig. 1C). Incidence increased $40 \%$ (from $10^{3}$ to $10^{6}$ sporidia $/ \mathrm{ml}$ ) in 1995 and $15 \%$ over this range of concentrations in 1997. The greatest increase in incidence occurred from $10^{3}$ to $10^{5} \mathrm{sporidia} / \mathrm{ml}$ in both years. Quadratic models best described the relationship between incidence and concentration of inoculum in 1995 (Fig. 1A: CV $=22 \%, r^{2}=$ 0.78 ) and 1997 (Fig. 1C: $\mathrm{CV}=23 \%, r^{2}=$ 0.42). In 1996, incidence and concentration of inoculum were not related consistently

Table 1. Mean squares for incidence of ears with galls and severity of ear galls of common smut on sweet corn hybrids inoculated with a range of concentrations of Ustilago maydis

\begin{tabular}{|c|c|c|c|c|c|c|c|}
\hline \multirow[b]{2}{*}{ Source of variation } & \multicolumn{3}{|c|}{ Incidence of ears with galls ${ }^{t}$} & \multicolumn{4}{|c|}{ Severity of ear galls ${ }^{\mathbf{u}}$} \\
\hline & 1995 & 1996 & 1997 & 1995 & 1996 & $1997 \mathbf{a}^{v}$ & $1997 b^{w}$ \\
\hline Replications & $848 \mathrm{~ns}^{\mathrm{x}}$ & $101 \mathrm{~ns}$ & $1,730 \mathrm{~ns}$ & $76 \mathrm{~ns}$ & $11 \mathrm{~ns}$ & $219 \mathrm{~ns}$ & $211 \mathrm{~ns}$ \\
\hline Hybrids $^{y}$ & $891 *$ & $2,822 * *$ & $3,155 *$ & $586 *$ & $189 * *$ & $415 \mathrm{~ns}$ & $473 \mathrm{~ns}$ \\
\hline Replications $\times$ hybrids & $339 \mathrm{~ns}$ & $125 \mathrm{~ns}$ & $889 * *$ & $169 \mathrm{~ns}$ & $21 \mathrm{~ns}$ & $299 * *$ & $324 * *$ \\
\hline Inoculum concentration ${ }^{\mathrm{z}}$ & $14,816 * *$ & $632 \mathrm{~ns}$ & $1,371 * *$ & $2,870 * *$ & $528 \mathrm{~ns}$ & $1,719 * *$ & $1,758 * *$ \\
\hline Hybrids $\times$ inoculum concentration & $213 \mathrm{~ns}$ & $1,649 * *$ & $99 \mathrm{~ns}$ & $140 \mathrm{~ns}$ & $330 * *$ & $84 *$ & $73 \mathrm{~ns}$ \\
\hline
\end{tabular}

${ }^{\mathrm{t}}$ Incidence of inoculated ears with galls per plot $(\%)=$ (number of ears per plot with galls)/(total number of ears per plot) $\times 100$.

${ }^{u}$ Severity of ear galls per plot $=($ sum of severity for all infected ears per plot $) /($ number of infected ears per plot $)$, with severity rated as percentage of the ear covered with galls.

v $1997 \mathrm{a}=1997$ data for all six hybrids evaluated.

${ }^{\mathrm{w}} 1997 \mathrm{~b}=1997$ data excluding the hybrid Dazzle

${ }^{\mathrm{x}} \mathrm{ns}$, *, and ** indicate non-significant at $P \geq 0.05$, significant at $P \geq 0.05$, and significant at $P \geq 0.01$, respectively.

y Eight sweet corn hybrids were evaluated in 1995; six hybrids were evaluated in 1996 and in 1997.

${ }^{\mathrm{z}}$ Concentration of inoculum ranged from $10^{3}$ to $10^{6}$ sporidia/ml. Data were transformed to $\log _{10}($ number of sporidia/ml) for statistical analysis. 
(Fig. 1B). Incidence increased with inocuand Temptation, decreased with inoculum concentration for Primetime and Ultimate, and fluctuated with inoculum concentration for Dazzle and GH 2690 (Fig. 1B).

Incidence of ears with galls was compared among hybrids when the main effect of hybrids was significant and the interaction of hybrids with inoculum concentration was not significant (Table 1). The hybrid Punchline had fewer ears with galls $(47 \%)$ than the other hybrids $(65 \%)$ evaluated in 1995 (Table 2). The six hybrids evaluated in 1997 separated into two groups. Incidence was lower $(61 \%)$ for hybrids Dazzle, GH 2690, and Ultimate than for Primetime, Punchline, and Temptation (86\%; Table 2). Ranking of hybrids for incidence varied for the three hybrids common to 1995 and 1997 (Table 2).

Severity of ear galls ranged from 10 to $89 \%$ with a mean of $41 \%$ in 1995 , from 2 to $45 \%$ with a mean of $17 \%$ in 1996 , and from 4 to $71 \%$ with a mean of $24 \%$ in 1997. Severity of ear galls resulting from natural infection ranged from 0 to $4 \%$ in 1996 and from 0 to $6 \%$ in 1997 . Severity lum concentration for hybrids Punchline

of ear galls differed among hybrids in 1995 and 1996 and among concentrations of inoculum in 1995 and 1997 (Table 1). The relationship between severity of ear galls and concentration of inoculum was consistent among all hybrids evaluated in 1995, differed among hybrids evaluated in 1996, and was consistent for five of the six hybrids evaluated in 1997 (Table 1).

Severity of ear galls increased with concentration of inoculum for all hybrids evaluated in 1995 and 1997, with the greatest increase from $10^{4}$ to $10^{5}$ sporidia/ml (Fig. 1D and Fig. 1F). A cubic model best described the relationship between severity and inoculum concentration in 1995 (CV $=28 \%, r^{2}=0.47$; Fig. 1D). In 1997, quadratic models best described the increase in severity with concentration of inoculum $\left(\mathrm{CV}=44 \%\right.$ and $r^{2}=0.36$ for five hybrids, and $\mathrm{CV}=38 \%$ and $r^{2}=0.24$ for Dazzle; Fig. 1F).

In 1996, severity of ear galls increased with inoculum concentration for hybrids GH 2690, Punchline, and Temptation, decreased with inoculum concentration for Primetime and Ultimate, and had little association with inoculum concentration

Table 2. Incidence of ears with galls and severity of ear galls of common smut on sweet corn hybrids inoculated with Ustilago maydis using the silk channel method of inoculation

\begin{tabular}{|c|c|c|c|}
\hline \multirow[b]{2}{*}{ Hybrid } & \multicolumn{2}{|c|}{ Incidence of ears with galls $(\%)^{x}$} & \multirow{2}{*}{$\frac{\text { Severity of ear galls }(\%)^{y}}{1995}$} \\
\hline & 1995 & 1997 & \\
\hline GSS 7887 & $72 \mathrm{a}^{\mathrm{z}}$ & & $41 \mathrm{bc}$ \\
\hline Ultimate & $69 \mathrm{ab}$ & $66 \mathrm{bcd}$ & $52 \mathrm{a}$ \\
\hline Primetime & $68 \mathrm{ab}$ & $91 \mathrm{a}$ & $45 \mathrm{ab}$ \\
\hline Daystar & $65 \mathrm{ab}$ & $\ldots$ & $41 \mathrm{bc}$ \\
\hline Frontier & $64 \mathrm{ab}$ & $\ldots$ & $38 \mathrm{c}$ \\
\hline Sch 5005 & $61 \mathrm{ab}$ & $\ldots$ & $34 \mathrm{c}$ \\
\hline Chieftan & $60 \mathrm{~b}$ & $\ldots$ & $45 \mathrm{ab}$ \\
\hline Punchline & $47 \mathrm{c}$ & $83 \mathrm{ab}$ & $33 c$ \\
\hline Dazzle & $\ldots$ & $59 \mathrm{~d}$ & $\ldots$ \\
\hline GH 2690 & $\ldots$ & $59 \mathrm{~cd}$ & $\ldots$ \\
\hline Temptation & $\ldots$ & $83 \mathrm{ab}$ & $\ldots$ \\
\hline
\end{tabular}

${ }^{\mathrm{x}}$ Incidence of inoculated ears with galls per plot $=$ (number of ears per plot with smut galls)/(total number of ears per plot) $\times 100$. Incidence means are averaged over four replications and four concentrations of inoculum.

${ }^{y}$ Severity of ear galls per plot $=($ sum of severity for all infected ears per plot $) /($ number of infected ears per plot). Severity per ear is rated as percentage of the ear covered with galls. Severity means are averaged over four replications and four concentrations of inoculum.

${ }^{\mathrm{z}}$ Means followed by the same letter are not significantly different $(P \geq 0.05)$.

Table 3. Mean squares for incidence of ears with galls and severity of ear galls of common smut on sweet corn inoculated in 1997 with a range of concentrations of Ustilago maydis by eight people

\begin{tabular}{|c|c|c|}
\hline Source of variation & $\begin{array}{l}\text { Incidence of ears } \\
\text { with galls }(\%)^{\mathrm{v}}\end{array}$ & $\begin{array}{c}\text { Severity of ear galls } \\
(\%)^{\mathrm{w}}\end{array}$ \\
\hline Replications & $345 *$ & $67 \mathrm{~ns}$ \\
\hline Inoculum concentration ${ }^{\mathrm{x}}$ & $16 \mathrm{~ns}^{\mathrm{y}}$ & $144 \mathrm{~ns}$ \\
\hline Replications $\times$ inoculum concentration & $62 \mathrm{~ns}$ & $28 \mathrm{~ns}$ \\
\hline People inoculating ${ }^{z}$ & $3,363 * *$ & $678 * *$ \\
\hline Replications $\times$ people inoculating & $84 \mathrm{~ns}$ & $14 \mathrm{~ns}$ \\
\hline Inoculum concentration $\times$ people inoculating & $265 * *$ & $49 * *$ \\
\hline
\end{tabular}

${ }^{\mathrm{v}}$ Incidence of inoculated ears with galls per plot $=$ (number of ears per plot with galls)/(total number of ears inoculated per plot $) \times 100$.

${ }^{\mathrm{w}}$ Severity of ear galls per plot $=$ (sum of severity of all infected ears per plot)/(number of infected ears per plot). Severity per ear is rated as percentage of the ear covered with galls.

${ }^{x}$ Concentration of inoculum ranged from $10^{3}$ to $10^{6}$ sporidia/ml. Data were transformed to $\log _{10}$ (number of sporidia/ml) for statistical analysis.

y Primary ears were inoculated by eight people.

${ }^{\mathrm{z}} \mathrm{ns}=$ nonsignificant at $P \geq 0.05 ; * *=$ significant at $P \geq 0.01$. for Dazzle (Fig. 1E). Much of the variation in severity appeared to be associated with variation among people inoculating, but this could not be tested in the ANOVA because of the experimental design.

Severity of ear galls ranged from $33 \%$ for hybrid Punchline to $52 \%$ for Ultimate in 1995 (Table 2). Ear galls were least severe on hybrids Daystar, Frontier, Punchline, and Sch 5005, and most severe on Chieftan, Primetime, and Ultimate in 1995.

In 1995, weight of smut per severity of infected ears did not vary significantly within the range of inoculum concentrations evaluated, nor among hybrids (data not presented).

Variation among people inoculating. In the 1997 experiment in which we evaluated variation among people inoculating, incidence of ears with galls ranged from 23 to $100 \%$ with a mean of $78 \%$. Severity of ear galls ranged from 7 to $47 \%$ with a mean of $26 \%$. Variation in incidence and severity was due primarily to variation among people carrying out inoculations and, secondarily, to interactions between people inoculating and concentration of inoculum (Table 3).

Incidence of ears with galls increased with concentration of inoculum for five people (E1, E2, I1, I3, and I5), but decreased with concentration of inoculum for I2 and I4 (Fig. 2A). The labels E and I represent people with at least one year of experience at inoculating with $U$. maydis and people with no prior experience at inoculating with $U$. maydis, respectively. The CV was below $10 \%$ for the four people with the highest incidence at all concentrations (E1, E2, E3, and I5), and ranged from 13 to $26 \%$ for the four people with the lowest incidence (I1, I2, I3, and I4; Table 4). Severity of ear galls increased with concentration of inoculum for six people, but decreased with concentration for two people (Fig. 2B). The CV was $14 \%$ for the four people with the highest mean severity of ear galls (E1, E2, E3, and I5), and was above $20 \%$ for the four people with the lowest severity of ear galls (I1, I2, I3, and I4; Table 4).

In the 1997 concentration study, deviations in incidence of ears with galls ranged from $35 \%$ below the BLUE to $37 \%$ above the BLUE of incidence. Deviations in severity of ear galls ranged from $18 \%$ below the BLUE to $46 \%$ above the BLUE of severity. Mean deviations from the BLUEs of incidence and severity were $>0$ for the two people experienced at inoculating with $U$. maydis, $\mathrm{E} 1$ and $\mathrm{E} 2$, and were $<0$ for $\mathrm{I} 1$ and I3 (Table 5). Deviations in mean incidence differed by as much as $26 \%$ (for E1 and I1) and deviations in mean severity differed by as much as 14\% (for I1 and I4).

\section{DISCUSSION}

Variation associated with the silk channel method of inoculating maize for com- 
mon smut in large-scale field trials is reduced by controlling the concentration of inoculum and by avoiding confounding variation among people inoculating with variation due to treatments. Large volumes of inoculum can be produced efficiently through centrifugation and resuspension without depriving sporidial suspensions of nutrients.

Variation among people carrying out inoculations was greater than variation due to concentration of inoculum. Incidence of ears with galls differed among people inoculating by as much as $30 \%$, and we observed a range of responses among people from an increase to a decrease in incidence with increasing concentration of inoculum. Although incidence of ears with galls increased by as much as $40 \%$, from $10^{3}$ to $10^{6}$ sporidia $/ \mathrm{ml}$, inoculum concentration can be controlled more readily in largescale field trials than can variation among people inoculating. Almost all of the people with high incidence and severity ratings and the most consistent results (lowest $\mathrm{CVs}$ ) had one or more years of prior experience inoculating with $U$. maydis. In the inoculum concentration studies, the variation among people inoculating occurred in

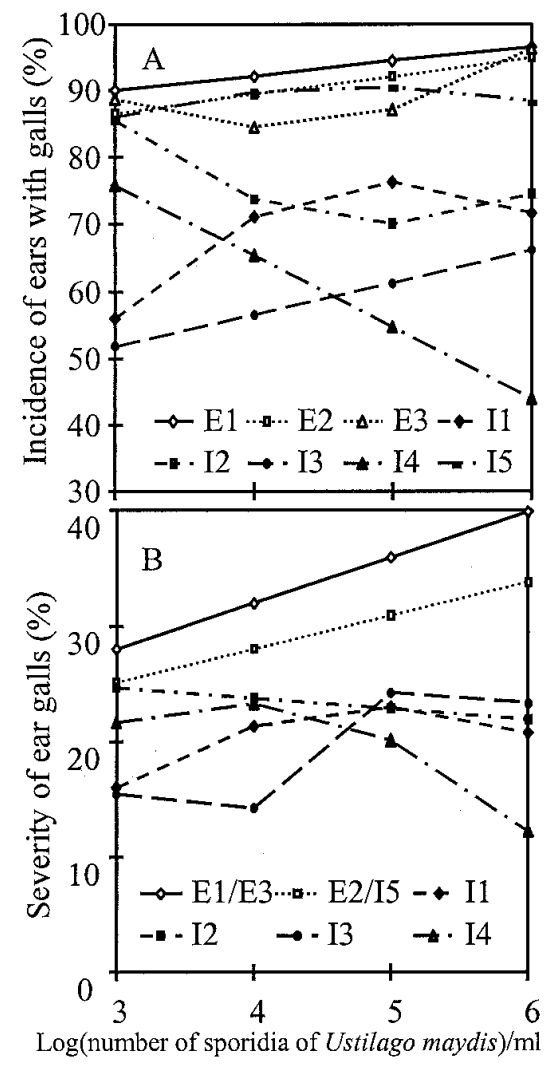

Fig. 2. (A) Incidence of ears with galls and (B) severity of ear galls of common smut on sweet corn inoculated in 1997 by eight people using a range of concentrations of Ustilago maydis. $\mathrm{E}$ and I indicate people with at least one year of experience and people with no prior experience, respectively, at inoculating with $U$. maydis.
1996 but was not evident in 1995, probably because the people inoculating in 1995 were graduate students or technicians with prior experience inoculating with $U$. maydis. In the 1996 concentration study, only one of seven people had any prior experience inoculating with $U$. maydis.

Low and variable smut ratings may be due to people not taking care to place the needle down the middle of the silk channel. If the needle is placed between husk leaves in the vicinity of the silk channel instead of directly in the silk channel, little or no inoculum is in contact with the silks. The needle also must be held within the silk channel until the entire $3 \mathrm{ml}$ of inoculum is dispensed into the silk channel. If the needle is removed too quickly, less inoculum is dispensed into the silk channel, which reduces incidence and severity ratings.

With inoculation methods that are sensitive to poor technique, experimental design must be used to avoid confounding variation among people inoculating with variation due to treatments, even in routine

Table 4. Incidence of ears with galls and severity of ear galls of common smut on sweet corn inoculated with a range of concentrations of Ustilago maydis by eight people in 1997

\begin{tabular}{lllr}
\hline People inoculating $^{\mathbf{u}}$ & Regression equation $^{\mathbf{v}}$ & $\boldsymbol{r}^{\mathbf{2 w}}$ & $\mathbf{C V}(\boldsymbol{\%})^{\mathbf{x}}$ \\
\hline Incidence of ears with galls $(\%)^{\mathbf{y}}$ & $\hat{Y}=83+2 x$ & & \\
E1 & $\hat{Y}=78+3 x$ & 0.38 & 4 \\
E2 & $\hat{Y}=141-27 x+3 x^{2}$ & 0.27 & 6 \\
E3 & 0.28 & 9 \\
I1 & $\hat{Y}=-50+50 x-5 x^{2}$ & 0.29 & 19 \\
I2 & $\hat{Y}=170-41 x+4 x^{2}$ & 0.28 & 13 \\
I3 & $\hat{Y}=37+5 x$ & 0.12 & 26 \\
I4 & $\hat{Y}=108-11 x$ & 0.63 & 16 \\
I5 & $\hat{Y}=57+14 x-2 x^{2}$ & 0.07 & 8 \\
Severity of ear galls ${ }^{z}$ & & & \\
E1/E3 & $\hat{Y}=16+4 x$ & 0.45 & 14 \\
E2/I5 & $\hat{Y}=16+3 x$ & 0.45 & 14 \\
I1 & $\hat{Y}=-23+19 x-2 x^{2}$ & 0.33 & 20 \\
I2 & $\hat{Y}=27-1 x$ & 0.05 & 21 \\
I3 & $\hat{Y}=308-214 x+50 x^{2}-4 x^{3}$ & 0.39 & 29 \\
I4 & $\hat{Y}=-12+19 x-2 x^{2}$ & 0.56 & 21 \\
\hline
\end{tabular}

" People labeled with an 'E' had at least one year of prior experience inoculating with U. maydis; people labeled with an 'I' had no prior experience inoculating for common smut.

${ }^{v}$ Regression equations describing the relationship between incidence of ears with galls or severity of ear galls $(\hat{Y})$ with concentration of inoculum of $U$. maydis $(x)$ ranging from $10^{3}$ to $10^{6}$ sporidia/ml.

${ }^{\mathrm{w}} r^{2}=$ coefficient of determination.

${ }^{x} \mathrm{CV}=$ coefficient of variation.

${ }^{\mathrm{y}}$ Incidence of inoculated ears with galls per plot $=$ (number of ears per plot with galls)/(total number ears inoculated per plot $) \times 100$.

${ }^{\mathrm{z}}$ Severity of ear galls per plot $=($ sum of severity for all infected ears per plot $) /($ number of infected ears per plot). Severity per ear rated as percentage of the ear covered with galls.

Table 5. Deviations in incidence of ears with galls and severity of ear galls of common smut for six people inoculating sweet corn with Ustilago maydis from the best linear unbiased estimate (BLUE) of incidence and severity of common smut in the 1997 inoculum concentration study ${ }^{\mathrm{v}}$

\begin{tabular}{|c|c|c|}
\hline Peoplew & $\begin{array}{l}\text { Deviation from the BLUE of } \\
\text { incidence of ears with galls }(\%)^{\mathrm{x}}\end{array}$ & $\begin{array}{l}\text { Deviation from the BLUE of } \\
\text { severity of ear galls }(\%)^{y}\end{array}$ \\
\hline E1 & $11.1 \pm 2.8 * * z$ & $4.8 \pm 1.7 * *$ \\
\hline E2 & $7.6 \pm 2.6 * *$ & $5.3 \pm 2.0 *$ \\
\hline I1 & $-15.1 \pm 3.7 * *$ & $-6.9 \pm 2.2 * *$ \\
\hline I2 & $-3.7 \pm 7.6 \mathrm{~ns}$ & $6.1 \pm 5.7 \mathrm{~ns}$ \\
\hline I3 & $-10.4 \pm 2.7 * *$ & $-3.8 \pm 1.4 *$ \\
\hline $\mathrm{I} 4$ & $3.6 \pm 4.1 \mathrm{~ns}$ & $7.1 \pm 4.1 \mathrm{~ns}$ \\
\hline
\end{tabular}

${ }^{v}$ BLUE of incidence of ears with galls or severity of ear galls at each of four concentrations of inoculum of $U$. maydis, calculated by regressing incidence or severity of ear galls against concentration of inoculum.

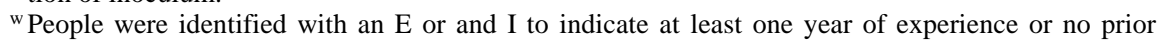
experience, respectively, at inoculating with $U$. maydis.

${ }^{\mathrm{x}}$ Incidence of inoculated ears with galls per plot $=$ (number of ears per plot with galls)/(total number ears inoculated per plot $) \times 100$. Deviation $=$ (incidence of ear with galls for a person inoculating with $U$. maydis) - (BLUE of incidence of ears with galls). Deviations averaged over four concentrations of inoculum and six hybrids.

${ }^{y}$ Severity per ear rated as percentage of the ear covered with galls. Severity of ear galls per plot $=$ (sum of severity of all infected ears per plot)/(number of infected ears per plot). Deviation = (severity of ear galls for a person inoculating with U. maydis) - (BLUE of severity of ear galls). Deviations averaged over four concentrations of inoculum and six hybrids.

${ }^{\mathrm{z}}$ Mean \pm standard error of deviation. *, **, and ns = significantly different from 0 at $P \geq 0.05$, significantly different from 0 at $P \geq 0.01$, and nonsignificantly different from 0 at $P \geq 0.05$, respectively. 
screenings. In breeding programs, it is difficult to control this variation because of the large volumes of material screened, ranging from hundreds to thousands of experimental entries varying in maturity. In addition, there may only be one replication of entries, in which case people cannot be blocked by replication. When one replicate of materials is evaluated, genotypes can be divided into blocks and people inoculating assigned to blocks of entries. Stratified selection for resistance to common smut within blocks would overcome the problem of variation among people inoculating, as long as each person had a consistent inoculation technique. However, our results indicate that some people have more variable inoculation techniques than others. Two of six people in the 1997 concentration study, and four of eight people in the 1997 variation among people study, had inconsistent inoculations. Breeding programs have limited access to experienced labor. This is compounded by the fact that inoculation for common smut occurs during pollination, when labor is in greatest demand. Variation among people inoculating may be the most important factor prohibiting application of the silk channel method of inoculation to commercial-scale programs breeding for resistance to common smut.

Concentration of inoculum must be controlled when screening for resistance to common smut with the silk channel method. Both incidence of ears with galls and severity of ear galls increased with concentration of inoculum. Incidence increased most rapidly between $10^{3}$ and $10^{5}$ sporidia/ml. Escapes ranged from 15 to $80 \%$ at $10^{3}$ to $10^{4}$ sporidia/ml and from 5 to $40 \%$ at $10^{5}$ to $10^{6} \mathrm{sporidia} / \mathrm{ml}$. Thus, concentrations between $10^{5}$ and $10^{6}$ sporidia/ml appear to minimize variation. When examining factors affecting resistance of maize to kernel infection by Fusarium graminearum (Schwabe), Reid and Hamilton (9) had difficulty distinguishing between resistant and susceptible genotypes when ears were inoculated with concentrations of $10^{7}$ sporidia/ml because ear rot was severe on all lines. Reid et al. (10) found that concentrations as low as $10^{4}$ spores $/ \mathrm{ml}$ differentiated between hybrids resistant and susceptible to ear rot caused by $F$. graminearum when using a method of silk inoculation similar to the one used for $U$. maydis in this study. They stated that concentrations $<5 \times 10^{5}$ spores/ml may not differentiate among genotypes in environments less conducive to ear rot. For common smut, inoculum concentrations $>10^{6}$ sporidia/ml may cause additional ear gall development, but the results of this study indicate a curvilinear response with maximum development of ear galls occurring between $10^{5}$ and $10^{6}$ sporidia/ml.

Large volumes of inoculum of $U$. maydis were produced rapidly and efficiently by excluding the centrifugation and resuspension steps from the protocol described by Snetselaar and Mims (11) and by determining concentration of inoculum using absorbance readings rather than hemocytometer counts. This greatly reduced the time required for preparing inoculum. It also removed the need for a centrifuge, making the protocol accessible to laboratories with minimal equipment such as those of small, private breeding programs. Snetselaar and Mims (11) recommended centrifugation to enhance the mating efficiency between compatible strains of $U$. maydis. A reduction in mating efficiency from nutrient-rich media may not have a visible effect on development of ear galls at high concentrations of inoculum such as $10^{6} \mathrm{sporidia} / \mathrm{ml}$, but may reduce efficiency of the silk inoculation method at lower concentrations of inoculum.

Applying the silk channel method of inoculation to commercial breeding programs requires the ability to differentiate among segregating materials. The limited number of commercial sweet corn hybrids evaluated in our study showed little variation in response to inoculation with $U$. maydis. The greatest difference we observed among hybrids was $20 \%$ incidence of ears with galls. The variation observed among people inoculating was greater than the variation among hybrids evaluated in this study. Commercially available sweet corn hybrids appear to have limited variation for resistance to common smut (7). The silk channel method is too variable for differentiating materials with intermediate levels of resistance, but may be valuable for identifying extreme levels of resistance to common smut which can be incorporated into breeding programs.

In parts of Central America, ear galls of common smut are harvested from naturally infected fields of maize and eaten $(4,16)$. Referred to as huitlacoche or maize mushrooms, this edible delicacy is popular in niche markets in the United States. Reports on production of huitlacoche as a cash crop have focused on gleaning infected ears from fields planted for sweet corn production. Efficient commercial production of huitlacoche would require a method of inducing ear galls consistently (15). Methods of inoculation have been examined for application in commercial production of huitlacoche $(6,8,14)$. Although additional modifications to the silk channel inoculation method are necessary to be practical in breeding programs, this method can be used for production of huitlacoche.

\section{LITERATURE CITED}

1. Christensen, J. J. 1963. Corn smut caused by Ustilago maydis. Am. Phytopathol. Soc. Monogr. 2.

2. du Toit, L. J., and Pataky, J. K. 1996. Effects of inoculum concentration and pollination on incidence of ear galls of common smut on sweet corn. (Abstr.) Phytopathology 86:S63.

3. Immer, F. R., and Christensen, J. J. 1928. Influence of environmental factors on the seasonal prevalence of corn smut. Phytopathology 18:589-598.

4. Kennedy, D. 1989. The Art of Mexican Cooking: Traditional Mexican Cooking for Aficionados. Bantam Books, New York.

5. Pataky, J. K. 1990. Production of cuitlacoche, Ustilago maydis. (Abstr.) Phytopathology 80:1044.

6. Pataky, J. K. 1991. Production of cuitlacoche (Ustilago maydis (DC) Corda) on sweet corn HortScience 26:1374-1377.

7. Pataky, J. K., Nankam, C., and Kerns, M. R. 1995. Evaluation of a silk-inoculation technique to differentiate reactions of sweet corn hybrids to common smut. Phytopathology 85:1323-1328.

8. Pope, D. D., and McCarter, S. M. 1992. Evaluation of inoculation methods for inducing common smut on corn ears. Phytopathology 82:950-955.

9. Reid, L. M., and Hamilton, R. I. 1996. Effects of inoculation position, timing, macroconidial concentration, and irrigation on resistance of maize to Fusarium graminearum infection through kernels. Can. J. Plant Pathol. 18:279285.

10. Reid, L. M., Hamilton, R. I., and Mather, D. E. 1995. Effect of macroconidial suspension volume and concentration on expression of resistance to Fusarium graminearum in maize. Plant Dis. 79:461-466.

11. Snetselaar, K. M., and Mims, C. W. 1993. Infection of maize stigmas by Ustilago maydis: Light and electron microscopy. Phytopathology. 83:843-850.

12. Steel, R. G. D., and Torrie, J. H. 1980. Principles and Procedures of Statistics. A Biometrical Approach, 2nd ed. McGraw-Hill, New York.

13. Thakur, R. P., Leonard, K. J., and Pataky, J. K. 1989. Smut gall development in adult corn plants inoculated with Ustilago maydis. Plant Dis. 73:921-925.

14. Valverde, M. E., Moghaddam, P. F., ZavalaGallardo, M. S., Pataky, J. K., Paredes-Lopez, O., and Pedersen, W. L. 1993. Yield and quality of huitlacoche on sweet corn inoculated with Ustilago maydis. HortScience 26:782785.

15. Valverde, M. E., Paredes-Lopez, O., Pataky, J. K, and Guevara-Lara, F. 1995. Huitlacoche (Ustilago maydis) as a food source-Biology, composition, and production. CRC Crit. Rev. Food Sci. Nutr. 35:191-229.

16. Vanegas, P. E., Valverde, M. E., ParedesLopez, O., and Pataky, J. K. 1995. Production of the edible fungus huitlacoche (Ustilago maydis _-Effect of maize genotype on chemical composition. J. Ferment. Bioeng. 80:104106.

17. Walter, J. M. 1935. Factors affecting the development of corn smut, Ustilago zeae (Beckm.) Unger. Minn. Agric. Exp. Stn. Tech. Bull. 111:1-67.

18. Zimmerman, S. A., and Pataky, J. K. 1992. Inoculation techniques to produce galls of common smut on ears of sweet corn. (Abstr.) Phytopathology 82:995. 